\title{
The Use of Prophylactic Antibiotics in Day Case Herniotomy at Abia State University Teaching Hospital, Aba, Nigeria
}

\author{
Samuel Chidi Ekpemo, ${ }^{1,}$, Sebastain Okwuchukwu Ekenze², Uchechukwu Obiora Ezomike ${ }^{2}$ \\ ${ }^{1}$ Department of Surgery, Abia State University, Aba, Nigeria \\ ${ }^{2}$ Department of Surgery, University of Nigeria, Enugu, Nigeria
}

Email address:

chidisamuelekpemo@gmail.com (S. C. Ekpemo)

${ }^{*}$ Corresponding author

\section{To cite this article:}

Samuel Chidi Ekpemo, Sebastain Okwuchukwu Ekenze, Uchechukwu Obiora Ezomike. The Use of Prophylactic Antibiotics in Day Case Herniotomy at Abia State University Teaching Hospital, Aba, Nigeria. Advances in Surgical Sciences. Vol. 6, No. 1, 2018 , pp. 36-40. doi: 10.11648/j.ass.20180601.17

Received: July 23, 2018; Accepted: August 17, 2018; Published: September 10, 2018

\begin{abstract}
Background: There has been tremendous improvement in the knowledge of prophylactic antibiotics use in surgery. There are controversies on the use of prophylactic antibiotics clean surgical cases. This study aims to determine if there is need to use prophylactic cefuroxime in day case herniotomy at the Abia State University Teaching Hospital Aba. Objective: To determine if there is need for prophylactic antibiotics in paediatric day case herniotomy and to compare the rate of surgical site infection in patients that receive preoperative cefuroxime to patients that did not receive it. Method: This was a hospital based prospective study carried out between April 2017 and April 2018 during which 126 herniotomy were performed as day cases at the Abia State University Teaching Hospital Aba. The patients were randomly placed into two groups: 63 patients in group A that received prophylactic cefuroxime at induction of anaesthesia and 63 patients in group B that did not receive cefuroxime. The two groups were compared to determine the factors that influenced development of surgical site infection. Results: There were $115(91.3 \%)$ males and $11(9.7 \%$ \} females. Their ages ranged from 1-14 years with a median of 2 years. The average duration of the operative procedure was 34.8 minutes (34.3 minutes in group A and 35.4 minutes in group B). After a follow up of 3 weeks, a total of 8 patients developed surgical site infection ( 3 patients in group A; 5 patients in group B) ( $p=0.358$ ). The duration of operation $(\mathrm{p}=0.549)$ and mode of transport $(\mathrm{p}=0.605)$ did not affect rate of surgical site infection. Conclusion: Development of surgical site infection after day case herniotomy in our hospital is not affected by the use of prophylactic antibiotics and duration of operation. The study confirms that day case herniotomy can be undertaken without prophylactic antibiotics.
\end{abstract}

Keywords: Day Case Herniotiomy, Prophylactic Antibiotics, Surgical Site Infection

\section{Introduction}

Surgical antimicrobial prophylaxis refers to the use of antimicrobial agent administered prior to an operation, its function is to reduce the burden of contamination from endogenous flora of patient's skin and exogenous sources of surgical site infection like surgical personnel, operating room environment, instrument and materials brought to the sterile field to a level manageable by host defenses[1]. Advances in infection control by using skin antisepsis, adequate sterilization of instruments, good surgical techniques such as less tissue trauma, obliteration of dead space and good haemostasis with the use of diathermy, tissue glues and haemostatic agents have made significant impact in the development of surgery. However, postoperative wound infection is still a major source of morbidity of surgical patients [1].

The use of pre-operative antibiotics to achieve adequate concentration in the tissue prior to contamination has significantly reduced the incidence of infection. [3-10]. The inappropriate use of prophylactic antibiotics in terms of the wrong choice of antibiotics, dosing, timing, duration and 
sensitivity to prevailing micro-organisms has been shown to increase antibiotics resistance and it is associated with poor clinical outcome. [11-15]. The antibiotics of choice should be the one which the prevailing organism is sensitive to, have larger volume of distribution, lower toxicity, longer half-life and single dose administration. [16-19].

Surgical site infections [20-29] have enormous impact on the patient quality of life due to increase in morbidity and mortality, duration of hospital admission and contribute substantially to the financial cost of patient's care. Administration of prophylactic antibiotics in clean contaminated and contaminated surgical procedures can decrease the rate of surgical site infection, morbidity and mortality, length of hospital stay and overall cost of surgical care. Cefuroxime [30] has a broad spectrum of coverage against gram positive and negative organisms. It is bactericidal and covers the spectrum of bacteria that causes surgical site infection.

The current practice at Abia State University Teaching Hospital Aba where prophylactic cefuroxime is being used for clean surgeries is not evidence based therefore a study is needed to convince practitioners if there is need to use prophylactic cefuroxime in clean day case herniotomy.

\section{Methodology}

The study is a hospital based prospective case control study. The patients recruited into the study after obtaining informed consent parents from the parents /guardian. They were randomized into two groups by tossing a special research coin with a head and tail: The head represents group A while the tail represents group B. Data collected include patient's initials, age, sex, weight, parents/guardian (age, level of education and occupation), mode of transport to the hospital, home distance from the hospital, diagnosis, type of operation, group A or group B, development of surgical site infection, duration of follow up, result of culture, antibiotics sensitivity to cultured organism and outcome. Ethical clearance was obtained from Abia State University Teaching Hospital ethical committee. The difference mean [31] formula $\mathrm{N}=\{\mathrm{r}+1 / \mathrm{r}\} \quad \mathrm{d}^{2}(\mathrm{zb}+\mathrm{za}\}^{2} /(\text { difference })^{2}$ was used to determine the sample size. Data were analysed using statistical package of social sciences (SPSS17.0 version, SPSS inc. Chicago 111\}. Chi -square test. [32,33] of significance using contingency tables, at 5\% level of significance and degree of freedom of 1 , was used for analysis. Analysis was in form of mean and percentage. Pvalues less than 0.05 was considered as significant and less than 0.01 as highly significant.

\section{Results}

\subsection{Demography}

The study was undertaken over a period of 13 months \{April 2017 and April 2018\}. During this period, there were 63 patients in each of the two groups. Overall, there were $115\{91.3 \%\}$ males and $11\{9.7 \%\}$ females. In group A, there were 56 males and 7 females while in group B there were 59 males and 4 females. Their ages ranged from 1-14years with a median of 2 years. The average weight of the patients was $16.7 \mathrm{Kg}$ \{range $8-46 \mathrm{~kg}$ \}. The average weight of group A patients was $18.3 \mathrm{Kg}$ and group B was $15.1 \mathrm{Kg}$. The average distance from home to the hospital is $12.1 \mathrm{~km}$ (range 10 $50 \mathrm{~km}$ ); for group A patients the average distance was $12.5 \mathrm{~km}$ while in group B patients it was $11.6 \mathrm{~km}$. A total of $74(58.7 \%)$ parents were civil servants, $11(8.7 \%)$ traders, $25(19.8 \%)$ non skilled workers, $8(6.3 \%)$ professionals and $8(6.3 \%)$ unemployed.

\subsection{Operative Procedures}

All the patients had inguinal herniotomy; in group A $46\{73 \%\}$ patients had right inguinal herniotomy and $17(27 \%)$ patients had left inguinal herniotomy while in group B 55(87.3\%) patients had right inguinal herniotomy and $8(12.7 \%)$ patients had left inguinal herniotomy. The average time for the procedures was 34.8 minutes; 34.3 minutes in group A patients and 35.4 minutes in group B patients. (Table $1)$.

Table 1. Diagnosis and duration of operation.

\begin{tabular}{lll}
\hline Parameter & Group A & Group B \\
\hline Right inguinal hernia & 46 & 55 \\
Left inguinal hernia & 17 & 8 \\
Average operation duration & 34.3 minutes & 35.4 minutes \\
\hline
\end{tabular}

\subsection{Follow up and Outcome}

All patients were followed up for 3 weeks. A total of $8(6.3 \%)$ patients developed surgical site infection. These comprised of $3(4.8 \%)$ patients in group $\mathrm{A}$ and $5(7.9 \%)$ patients in group B. (Table 2)

Table 2. Outcome.

\begin{tabular}{lll}
\hline Wound status & Group A & Group B \\
\hline Infected & 3 & 5 \\
Not infected & 60 & 58 \\
\hline
\end{tabular}

P-value 0.358 using a $2 \times 2$ contingency table ${ }^{33}$

\subsection{Mode of Transport}

The 65 patients that used private vehicles to the hospital, 4 patients had surgical site infection while 4 patients developed surgical site infection out of the 61 patients that used public vehicles. P-value of 0.60 (Table 3).

Table 3. Mode of transport and Surgical site infection.

\begin{tabular}{lll}
\hline Mode of transport & Surgical site infection & No surgical site infection \\
\hline Private vehicle & 4 & 61 \\
Public vehicle & 4 & 57 \\
\hline
\end{tabular}

\subsection{Duration of Operation}

The 68 patients that the duration of operation was greater than 34 minutes, four patients developed surgical site infection while 4 patients developed surgical site infection out of the 58 patients that the duration of operation was less 
than 34 minutes. P-value of 0.549. (Table 4)

Table 4. Duration of operation and development of surgical site infection.

\begin{tabular}{lll}
\hline Duration & Surgical site infection & No surgical site infection \\
\hline$>34$ minutes & 4 & 64 \\
$<34$ minutes & 4 & 54 \\
\hline
\end{tabular}

\subsection{Bacterial Isolates and Antibiotics Sensitivity in Infected Cases}

Three cases of surgical site infection in group A that received preoperative antibiotics grew Staphylococcus aerus in the 3 cases. The group B patients that did not received antibiotics also grew Staphylococcus aerus in 3 cases and Klebsiella in 2 cases. The antibiotic pattern shows a common sensitivity to cefuroxime. They were resistant to erythromycin and gentamycin (Table 5)

Table 5. Bacterial isolates and antibiotics sensitivity.

\begin{tabular}{lllll}
\hline Bacterial isolate & Group A & Group B & Sensitivity to & Resistant to \\
\hline Staphylococcus & 3 & 3 & Cefuroxime & $\begin{array}{l}\text { Erythromycin } \\
\text { Gentamycin }\end{array}$ \\
Klebsiella & - & 2 & Cefuroxime & $\begin{array}{l}\text { Erythromycin } \\
\text { Gentamycin }\end{array}$ \\
\hline
\end{tabular}

\section{Discussion}

The pattern of sex distribution in this study shows a predominance of males over females in both groups. In group $\mathrm{A}$, there were 56 males and seven females in the ratio of $8: 1$. In group $B$, there were 59 males and four females in the ratio of 14:1. This corresponds with the finding of paediatric day case prophylactic study in other centers in Nigeria [17, 18,34] and United Kingdom. [35, 37]. It is known that paediatric hernia is common in males. The younger ages dominated in this study with 93(73\%) patients below the age of five years. This finding is similar to other studies $[19,20,34]$ where the patients were operated to correct congenital hernias as early as possible to prevent intestinal obstruction.

The results of this study showed that the majority are domicile within $10 \mathrm{~km}$ from the hospital with easy access in case of any emergencies which is comparable with study in Ilorin [34] but at variance with study done at Ile-Ife [19] where majority live at more than $10 \mathrm{~km}$ from the hospital. Longer distance from the hospital may delay patient presentation to the hospital in emergencies following day case surgery. The distance from the hospital did not affect the rate of surgical site infection in our study.

Sixty-one percent (61\%) of the parents had tertiary education, which is similar to a study done at Ilorin but is at variance with study done at Ile-Ife [19] where half of the mothers $(47.7 \%)$ do not have secondary education. The parent's educational level did not affect the incidence of surgical site infection. The majority of the parents were civil servants in comparison with studies done elsewhere in Nigeria [34].

This study showed that equal number of patients used both public and private transport which does not agree with findings of other studies in our sub-region[19, 34] in which a large number of patients use public transport. This does not conform to standard in high income countries [35-37] where private vehicles were used as primary mode of transport. The cross tabulation of mode of transport with complication showed no significant statistical difference between the two groups in our study. The use of public transport may lead to increase stress, metabolic response to trauma and rate of contamination that may lead to higher wound infection rate.

The mean operation time was 34.8 minutes which was short in comparison with other studies done in Nigeria [19, 34]. The operation time in this study did not affect the patient outcome which is similar to other studies done in Nigeria. Operation time that is more than the half life of the antibiotics can increase the rate of surgical site infections, this will necessitate a repeat dose of the prophylactic antibiotics [38].

The surgical site infection rate in this study was $4.7 \%$ (3 out 0 f 63 ) patients in group A that used antibiotics and $7.9 \%$ (5 out of 63) patients in group B that did not use antibiotics. There was no statistical significant difference in the rate of surgical site infection between the two groups. This rate of surgical site infection is comparable to other studies done elsewhere in Nigeria $[19,34]$ but high when compared with studies done in United Kingdom [35-37]. A similar finding has been reported in previous studies from high income and other lower income countries $[38,39]$. This may indicate that there are other factors involved in the development of surgical site infection. Studies have shown that factors such as inadequate haemostasis, hypothermia, dead space, rough tissue handling, improper use of suture materials and inadvertent entry into hollow viscus may play a more vital role in the development of surgical site infection after clean surgical procedures. The importance of this is that efforts are to be directed towards obviating these factors rather than concentrating on giving antibiotics. On the other hand [3842], some studies have shown that in settings where the operating environment might be contaminated or the hygienic state of the patient's home is uncertain, it may be prudent to give prophylactic antibiotics to minimize or prevent surgical site infection.

The infected wounds were swabbed and microscopy, culture and sensitivity test were done. The culture yield showed staphylococcus specie as the commonest infecting organism. All isolates were resistant to erythromycin and gentamycin but sensitive to cefuroxime. This bacteriology is in line with findings on nosocomial infection within and outside Nigeria [11, 43].

This study showed that the difference between the rates of surgical site infection in the two groups studied was not statistically significant. This finding is comparable with that of previous studies in Nigeria [19, 29, 34] other lower income countries $[40,41]$ and high income countries [36, 37]. Appropriate patient selection, proper counselling of parents and care givers will make day case paediatric hernia surgery feasible without the use of prophylactic antibiotics in 
our sub-region.

\section{Conclusion}

This study was a hospital case control study in which patients were randomized into two groups, cefuroxime was used for the case and no antibiotics was given for the control. Results showrd that in paediatric day case herniotomy, prophylactic cefuroxime did not significantly decrease the development of post-operative surgical site infection. The study confirms that day case herniotomy is safe without use of prophylactic antibiotics in our setting.

\section{References}

[1] Kaiser BA, Herrington JR, Jacob LM, Albert CR, John LS. Antmicrobial prophylaxis in surgery. N Engl J Med 1986; 315:1129-38.

[2] Bratzler WD, Houck PM. Antimicrobial prophylaxis in surgery. Clin Infect Dis 2004; 38:1706-15.

[3] Lim VKE, Cheong YM, Suleiman AP. Pattern of antibiotic usage in Malaysia. Singapore Med J 1993; 34: 525-8.

[4] Classen CD, Evans RS, Pestonik SL, Horn SD, Menlove RL, Buckee JP. The timing of prophylactic administration of antibiotics and risk of wound infection. N Engl J Med 1992; 326: 281-6.

[5] Ansari SA, Saddique M, Azim W. Antibiotic prophylaxis in clean surgery. Biomedica 2005; 21:122-4.

[6] Barone AJ, Hermes-Desantis ER. Adverse drug reactions and drug induced diseases. In: Herfinal TE, Gourley R. D (Editors). Textbook of Therapeutics: Drugs and disease management. $6^{\text {th }}$ edition Baltimore: Williams and Wilkins 1996. pp10-30.

[7] Wenzel PR. Preoperative antibiotics prophylaxis. N Engl J Med 1992; 32:337-9.

[8] Lindblad WJ. The considerations of determining if a natural product is an effective wound healing agent. Int J low Extrem wounds 2008 ; 7:73-81.

[9] Forrest RD. Early history of wound treatment. J R Soc Med 1992; 75:198-205.

[10] Foster W, Raoult A. Early description of antibiosis. J R Coll Gen Pract 1974; 24:889-94.

[11] Waksman SA. What is antibiotic substance? Mycolia 1947; 39:565-9.

[12] Bosch F, Rosich L. The contributions of Paul Ehrlich: a tribute on the occasion of the centenary of his noble prize. Pharmacology 2008; 82:171-9.

[13] Burke JF. The effective period of preventive antibiotic action in experimental incisions and dermal lesions. Surg 1961; 50:160-8.

[14] Talon D, Mourey F, Tourgtier S, Marie O, Arlet G. Evaluation of current practices in surgical antimicrobial prophylaxis before and after implementation of local guidelines. J Hosp Infect -2001; 49:193-8.
[15] Gorbash SL. Evaluation of new anti-infective drugs for surgical prophylaxis. Clin. Infect. Dis 1992; 15: 313-38.

[16] Page CP, Bohen JM, Fletcher JR, Mcmanus AT, Solomon JS, Wittman DH. Antimicrbial prophylaxis for surgical wounds in Guidelines for clinical care. Arch Surg 1993; 128:78-88.

[17] Shapiro M, Townsend TR, Rosner B. Use of antimicrobial drugs in general hospitals: Patterns of prophylaxis. N Engl J Med 1979; 301:351-5.

[18] Gottrup F. Prevention of surgical wound infections. N Engl J Med 2000; 324:202-[19]. Osuigwe AN, Ekwunife CN, Ihekwoba $\mathrm{CH}$. Use of prophylactic antibiotics in paediatric day case surgery at NAUTH Nnewi Nigeria: A randomized double blind study. Trop. Doct 2006; 36:42-4.

[19] Usang UE, Sowande OA, Adejuigbe O, Bakare TI, Ademuyiwa OA. The role of preoperative antibiotics in the prevention of wound infection after day case surgery for inguinal hernia in children at Ile-Ife, Nigeria. Paediatr Surg Int 2008; 10:1181-5.

[20] Magram AJ, Horan TC, Mitchele LP, William RJ. Guideline for prevention of surgical site infection. Infect. Control Hosp. Epidemiol. 1999; 20:247.

[21] Kessler RW, Guhlow LT, Saulsbury FT. Prophylactic antibiotics in paediatric surgery. Paeditrics 1982; 68:1-3.[

[22] .Berrios-Torres SI, Umscheid CA, Bratzer DW. Center of disease control and prevention guidelines for prevention of surgical site infection JAMA Surg 2017

[23] Bratzler WD, Dellinger PE, Olsen KM, Peri TM. ASHP therapeutic guidelines on Antimicrobial prophylaxis in surgery. Am J Health-Syst. Pharm 2013; 70: 195-283.

[24] Dudgeon DC, Anderson KD, Ascheraft KW, Boeckman CR, Ellis DG, Fonkalsrud et al. Antibiotics prophylaxis in paediatric surgical patients. Paediatrics 1984:74-9.

[25] Hirschmann JV, Inui TS. Antimicrobial prophylaxis. A critique of recent trials. Rev Infect Dis 1980; 2:1-23.

[26] Miles AA, Miles EM, Burke J. The value and defense reactions of the skin to the primary lodgment of bacteria. Br J Exp Pathol. 1957; 38: 79-96.

[27] Nagvi SH, Dunkle HM, Timmerman KJ. Antibiotic usage in a paediatric medical centre. JAMA 1979; 242:1981-4.

[28] Schollenberg E, Abritton WL. Antibiotic misuse in a paediatric teaching hospital. Can Med Assoc J 1980; 122:4952.

[29] Ameh EA, Mshelbwala PM, Nasir AA, Lukong CS, Jabo BA, Anumah et al. Surgical site infection in children: prospective analysis of the burden and risk factors in a sub-Saharan African setting. Surg Infect. 2009 10(2):105-9.

[30] .Jawetz E. Penicillins and cephalosporins. In: Katzung BG (Editor) Basic and Clinical Pharmacology. $6^{\text {th }}$ edition Connecticut Appleton and Lange 1992 pp680-6.

[31] .Sathian B, Sreedharam J, Baboo NS. Relevance of sample size determination in medical research. NepJOL. 2010; 1:4$10 /$

[32] Diener-West M. Use of Chi Square statistics. John Hopkins 2008; pp1-42. 
[33] Goyal RC. Research Methodology for Health Professionals. New Delhi, Jaypee 2013; pp165-7.

[34] Abdur-Rahmann LO, Kolawale IK, Adeniran AA. Paediatric day case surgery: Experience from tertiary health institution in Nigeria. Ann Afr Med. Vol 8 2009; 163-7.

[35] .Salder GP, Watkins G, Richard H, Foster ME. Day case paediatric surgery: the only choice. An R Coll Surg Engl $1992 ; 130-3$.

[36] Calder F, Hurley p, Fernandez C. Paediatric day case surgery in a district general hospital: a safe option. Ann R Coll Surg Engl 2001; 1:83.

[37] Bronsther B, Abrams MW, Elboim C. Inguinal hernias in children-a study of 1000 cases and a review of the literature. J Am Med Women Assoc 1972; S27:522-52.

[38] [40].Yousuf M, Hussain M. Need and duration of antibiotic therapy in clean and clean contaminated. JPMA 2000; Jul: 284-7.
[39] Anaya DA, Dellinger EP. Surgical infections and choice of antibiotics. In: Townsend CM. Beauchamp RD, Evers BM, Mattox KL (Editors). Sabiston Textbook of Surgery $17^{\text {th }}$ edition. Philadephia. W B Saunders company 2004. Pp257-82.

[40] Cuschieeri SA, Steele RJ. Patients undergoing surgery. In: Cuscheeri SA, Steele RJ, Moosa AR (Editors). Essentials Surgical practice. $4^{\text {th }}$ edition. Oxford. Arnold 2000 pp372-3.

[41] .Bhatti HA, Shadid A, Ahmad T, Qurehi. Role of antibiotics in clean surgery. Paskistan Postgrad. Med. J 2000; 11:87-8.

[42] .Khan N, Chemoprophylaxis in operative cases. Parkistan Armed Forces Med J. 1998; 12:40-5.

[43] Mishiru SF, Law DJ, Jeffrey PJ. Factors affecting the incidence of post-operative wound infection. J. Hosp. Infect. 1990; 16:223-30. 